\title{
META ANALISIS EFEKTIFITAS BELAJAR SISWA SECARA DARING MENGGUNAKAN APLIKASI EDMODO
}

\author{
${ }^{1}$ Nadiya, ${ }^{2}$ Dhimas Eza \\ Pendidikan Fisika, Universitas Indraprasta PGRI \\ Jl. Raya Tengah No.80, RT.06/RW.01, Gedong, Kec. Ps. Rebo, Kota Jakarta Timur, Daerah \\ Khusus Ibukota Jakarta 13760 \\ 1nadiyaagustina.na@gmail.com,${ }^{2}$ dhimazeza17@gmail.com
}

\begin{abstract}
ABSTRAK
Dengan berkembangnya teknologi baik secara langsung maupun tidak langsung dapat merubah seseorang dalam berkomunikasi, bersosialisasi dan belajar. Hal ini adalah sebuah tantangan untuk para guru supaya dapat menggunakan teknologi secara optimal dan dapat mempermudah interaksi dengan siswa dalam proses belajar mengajar baik di dalam kelas maupun di luar kelas sehingga indikator dalam ruang pembelajaran dapat tercapai. Pendidikan yang bermutu tidak terlepas dari peran guru dalam proses pembelajaran. Guru yang profesional akan menciptakan generasi masa yang akan datang sehingga memiliki sikap, pengetahuan dan keterampilan yang berkualitas. Di saat pandemi Covid-19 ini kita tidak bisa bertemu bertatap muka secara langsung dikarenakan membahayakan kesehatan guru maupun siswa dan disarankan belajar melalui alat tekhnologi agar para siswa masih bisa mengikuti pembelajaran dan instruksi dari guru. Alat tekhnologi yang biasanya kita pakai adalah Aplikasi Edmodo di mana aplikasi ini mempermudah siswa untuk mengerjakan tugas-tugas yang sudah guru berikan. Edmodo adalah sebuah platform sosial network bagi guru dan siswa untuk berbagi ide, file, agenda kegiatan dan penugasan. Edmodo dirancang untuk menciptakan interaksi dengan guru dan siswa yang menekankan pada komunikasi yang cepat, pooling, penugasan, berbagi ide, dan banyak hal lagi. Penelitian bertujuan untuk: 1) mengetahui apakah pembelajaran yang menggunakan Aplikasi Edmodo (eksperimen) lebih baik dibandingkan dengan pembelajaran tanpa menggunakan Aplikasi Edmodo (konvensional), 2) mengetahui apakah siswa yang belajar dengan menggunakan Aplikasi Edmodo bersikap positif terhadap pembelajaran. Pada penelitian kualitatif ini dengan menggunakan metode analisis.
\end{abstract}

Kata Kunci : Efektifitas Belajar Siswa, Daring, dan Aplikasi Edmodo.

\section{PENDAHULUAN}

Edmodo dikembangkan pada akhir tahun 2008 oleh Nic Borg dan Jeff O'hara yang berkeyakinan bahwa perlu dikembangkan lingkungan kampus yang terhubung dengan semua aktifitas di dunia. Edmodo adalah platform media sosial yang sering digambarkan sebagai Facebook untuk kampus dan dapat berfungsi lebih banyak lagi sesuai dengan kebutuhan. "Edmodo merupakan aplikasi yang menarik bagi dosen dan mahasiswa dengan elemen sosial yang menyerupai Facebook, tapi sesungguhnya ada nilai lebih besar dalam aplikasi edukasi berbasis jejaring sosial ini" (Basori 2013).

Peraturan Menteri Pendidikan dan Kebudayaan Republik Indonesia Nomor 49 Tahun 2014 tentang Standar Nasional Pendidikan Tinggi pasal 14 menyebutkan bahwa proses pembelajaran melalui kegiatan kurikuler wajib menggunakan metode pembelajaran yang efektif. Efektif yang dimaksud oleh peraturan tersebut mempunyai arti bahwa proses pembelajaran harus menggunakan waktu secara optimal dan bersifat kolaboratif. Artinya, interaksi antara guru dan siswa harus tetap terjaga dan semua 
materi terinternalisasi dengan baik sesuai dengan waktu yang telah direncanakan. Kriteria yang disampaikan pada peraturan tersebut sebenarnya bisa dicapai dengan memanfaatkan produk Tekhnologi Informasi dan Komunikasi atau peran teknologi untuk mendukung proses pembelajaran di dalam kelas.

Fakta di lapangan menunjukkan bahwa proses pembelajaran selama ini masih dilakukan dengan cara bertatap muka secara langsung, akan tetapi semenjak tanggal 15 Maret 2020 sampai 17 Juli 2020 diberlakukan PSBB (Pembatasan Sosial Berskala Besar) dan seharusnya pembelajaran dalam mengajar harus tetap berlangsung. Untuk mengatasi masalah ini maka dicari jalan keluar dengan menggunakan Aplikasi Edmodo agar mempermudah guru dengan siswa dalam menyampaikan materi pembelajaran tersebut. Aplikasi Edmodo merupakan suatu sistem Aplikasi yang sederhana dan mudah digunakan oleh para siswa. Mudah dan sederhana yang dimaksud adalah berisi:

1) Guru memberikan pesan kepada siswanya.

2) Guru memberikan file materi yang akan disampaikannya.

3) Guru memberikan media video yang akan menjelaskan file materi.

4) Siswa bisa bertanya langsung kepada guru di kolom komentar dan pesan pribadi.

5) Aplikasi Edmodo ini bisa memberikan jadwal pemberian tugas dan pengumpulan tugas.

6) Aplikasi Edmodo adalah pembelajaran sosial untuk guru,siswa dan orang tua.

7) Guru bisa langsung memposting nilai dan tugas kepada siswa.

8) Guru bisa membedakan dan mengindividualisasikan pembelajaran melalui penciptaan subkelompok.
Berdasarkan uraian di atas, pengenalan, dan penggunaan media sosial Edmodo bagi siswa dalam proses belajar mengajar sangatlah tepat untuk dilakukan. Keterampilan penggunaan media sosial yang dimiliki oleh siswa tentu akan sangat mempermudah proses pembelajaran mengajar dengan menggunakan Edmodo yang memiliki keunggulan serta ingin dilihat efektifitas dari penggunaan edmodo itu terhadap komunikasi guru pada siswa tersebut.

Edmodo adalah pembelajaran berdasarkan jejaring sosial yang aman dan gratis dalam mempermudah guru untuk membuat dan mengelola kelas virtual sehingga siswa dapat terhubung dengan teman sekelas dan guru kapan saja dan di mana saja. Edmodo dikembangkan oleh Nicolas Borg and Jeff O'Hara sebagai platform pembelajaran untuk berkolaborasi dan terhubung antara siswa dan guru dalam berbagi konten pendidikan mengelola tugas dan menangani pemberitahuan setiap aktifitas.

Edmodo adalah pembelajaran gratis dan aman yang tersedia di www.edmodo.com. Website ini terlihat mirip dengan facebook, akan tetapi jauh lebih pribadi dan lebih aman untuk dilingkungan belajar. Penelitian ini bertujuan untuk menyelidiki bagaimana seorang guru non-digital-pribumi dapat menggunakan edmodo untuk mengatur dan menjalankan secara online (daring). Setiap kelas bagi murid-muridnya untuk bekerja secara online bersamaan dengan kelas fisik serta bisa berkomunikasi dari edmodo untuk guru lainnya.

Manfaat menggunakan media Aplikasi Edmodo dalam pembelajaran guru terhadap siswa bisa dijelaskan sebagai berikut:

a. Mengubah belajar siswa yang pasif kepada budaya belajar aktif, maka terbentuknya belajar siswa yang mandiri 
b. Orang tua bisa memantau langsung kegiatan anaknya terhadap guruny

c. Meningkatkan kualitas pembelajaran mengajar guru kepada siswa

d. Menambah wawasan belajar bagi siswa

e. Membagikan dan memperluas produk dan layanan baru

f. Edmodo merupakan wahana komunikasi dan diskusi yang sangat efiesien untuk para guru dan murid.

g. Mempermudah guru memberikan soal/tugas dimana saja dan kapan saja.

Berdasarkan pemaparan diatas, kita dapat simpulkan bahwa media pembelajaran Aplikasi Edmodo membantu guru untuk memperkuat rencana pembelajaran mengajar.

Fitur Edmodo Dalam mendukung proses pembelajaran, edmodo dilengkapi dengan beberapa aktivitas pembelajaran, seperti quiz, assignment, polling, grade book, library, award badges, dan parent code. Untuk bahan ajar, edmodo mendukung bahan ajar berupa file dan links ( Kamarga, 2011:267).

Dapat kita jelaskan tentang fitur fitur Aplikasi Edmodo sebagai berikut:

a) Quiz. Fitur ini hanya bisa dibuat oleh para guru, sedangkan siswa tidak bisa mengakses untuk membuat quiz. Mereka hanya bisa mengerjakan soal/tugas dari guru. Fitur Aplikasi Edmodo ini telah lengkap dengan batasan waktu pengerjaan soal, informasi tentang kuis yang akan dibuat, judul kuis dan tampilan kuis.

b) Assignment. Fitur ini untuk memberikan tugas dari guru kepada murid secara online. Aplikasi ini mempunyai kelebihan yaitu lengkap dengan waktu terkahir pengumpulan tugas dari guru, fitur attach file ini bisa memudahkan siswa mengirimkan kepada guru dalam bentuk file document (pdf, xls, ppt, doc), dan untuk tombol "Turn in" pada assignment bertujuan bahwa siswa telah menyeleseikan tugas mereka.

c) Polling. Fitur ini digunakan untuk guru dibagikan kepada siswa untuk mengetahui bagaimana tanggapan siswa mengenai hal tertnetu terhadap mata pelajaran yang telah di berikan pada guru.

d) Gradebook. Fitur ini persis seperti catatan nilai siswa yang bisa diisi secara manual atau otomatis sedangkan seorang siswa dapat melihat hasil rekapan nilai dalam bentuk grafik dan penilaian secara langsung

e) Library. Fitur ini guru bisa mencari bahan ajar seperti materi, presentasi, gambar, video, sumber referensi, konten digital dan lainnya. Aplikasi ini sebagai wadah untuk menampung berbagai file dan link yang sudah dimiliki oleh guru maupun murid.

f) Award Badges. Fitur ini biasa digunakan untuk penghargaan kepada siswa individu maupun berkelompok. Badges biasanya diberikan kepada siswa yang telah mengerjakan tugas dari guru dengan sangat baik dan berprestasi, dan bisa dijadikan ajang motivasi untuk murid yang sedang mengerjakan tugas agar lebih bersemangat lagi untuk mendapatkan award badges ini.

g) Parent code. Fitur ini memberi kesempatan kepada orang tua siswa bergabung dan memantau segala aktifitas belajar dan prestasi putraputrinya, guru harus mengakses kode untuk wali murid dan membagikannya pada masing- masing orang tua, orang tua murid dapat mengklik nama kelas anaknya. 


\section{METODE PENELITIAN}

Ada Jenis penelitian yang di pakai oleh peneliti adalah jenis penelitian kuanitatif dengan metode analisis (meta analisis). Jenis penelitian adalah penelitian eksperimen semu (quasy eksperiment research). Meta-analisis merupakan teknik statistika penelitian sejenis yang mengabungkan dua atau lebih sehingga diperoleh paduan data secara kuantitatif. Dilihat dari prosesnya, meta-analisis merupakan suatu studi yang dilakukan dengan rekapitulasi data yang sudah ada tanpa melakukan manipulasi eksperimen.

Penelitian ini merupakan analisis kuantitatif dengan menggunakan sejumlah data yang cukup banyak dan menerapkan metode statistika melalui hasil-hasil penelitian yang sudah dilakukan. Tujuan utama penelitian ini adalah efektivitas belajar siswa secara daring menggunakan aplikasi edmodo dari berbagai sumber yang sudah ada.

Prosedur penelitian ini disesuaikan dengan langkah-langkah meta analisis yang disarankan oleh Sujipto (1995) yaitu mengartikan meta analisis sebagai salah satu upaya untuk merangkum berbagai hasil penelitian secara kuantitatif.

Adapun hal-hal yang dilakukan dalam penelitian ini, yaitu:

1. mengumpul data-data yang sejenis dengan penelitian

2. menganalisa dari data yang sudah terkumpul tersebut

3. merangkum dan menarik kesimpulan dari data-data yang sudah di analisa

\section{HASIL DAN PEMBAHASAN}

Berdasarkan dari hasil analisa yang sudah dilakukan, ada beberapa hasil efektivitas belajar siswa secara daring menggunakan aplikasi edmodo yaitu:
1. Dari jurnal berjudul "APLIKASI EDMODO SEBAGAI MEDIA PEMBELAJARAN ELEARNING".

Edmodo adalah salah satu media yang dapat digunakan. Sebagai media pembelajaran e-learning edmodo memiliki banyak kelebihan dibandingkan media pembelajaran yang lain. Kelebihan itu diantaranya adalah fitur-fitur yang ada juga sangat membantu guru dalam membuat kelas virtual yang keadaannya dapat disesuaikan dengan kelas nyata. Seperti fitur penugasan yang bisa langsung dinilai oleh guru setelah batas waktu pengumpulan. Selain itu edmodo sangat mudah digunakan oleh guru, melalui edmodo guru juga bisa melakukan diskusi seperti di kelas nyata. Hanya saja media pembelajaran edmodo sangat bergantung dengan koneksi internet.

2. Dari jurnal berjudul "PEMBELAJARAN BERBASIS EDMODO DAN MOTIVASI BELAJAR PESERTA DIDIK DI SMKN 2 PALOPO".

Berdasarkan hasil analisis data bahwa penerapan pembelajaran berbasis Edmodo di SMKN 2 Palopo berlangsung secara efektif sehingga peserta didik di SMKN 2 Palopo termotivasi dalam mengikuti pembelajaran berbasis Edmodo. Hal ini membuktikan bahwa terdapat pengaruh signifikan penerapan pembelajaran berbasis Edmodo terhadap motivasi belajar peserta didik di SMKN 2 Palopo.

3. Dari jurnal berjudul "EFEKTIVITAS PENGGUNAAN MEDIA EDMODO PADA PEMBELAJARAN MATEMATIKA EKONOMI TERHADAP KOMUNIKASI MATEMATIS"

Berdasarkan hasil meta-analisis dari peneliti dari jurnal tersebut adalah belajar menggunakan edmodo (daring) efektif dalam pembelajaran karena memberikan pengalaman yang baik yaitu memudahkan peserta didik dalam mengerjakan soal dan dapat 
mndiskusikan dari contoh soal dan latihan soal sehingga komunikasi lebih efektif dan menghemat waktu.

4. Dari jurnal berjudul "EFEKTIFITAS PENGGUNAAN E-LEARNING BERBASIS EDMODO TERHADAP KEMAMPUAN KOMUNIKASI MATEMATIKA"

Berdasarkan hasil meta-analisis dari peneliti mengenai jurnal tersebut adalah bahwa ada perbedaan kemampuan komunikasi yang signifikan antara peserta didik yang diajar dengan media edmodo dan peserta didik yang tidak diajar dengan media edmodo.

Hal ini disebababkan oleh beberapa factor yang mempengaruhi yaitu factor internal dan factor eksternal. Faktor internal yaitu dari peserta didik sendiri seperti kemampuan komunikasi peserta didik yang mempengaruhi respon pada saat pembelajaran berlangsung. Sedangkan factor eksternalnya yaitu waktu pembelajaran yang kondusif.

5. Dari jurnal berjudul "PENGARUH EFEKTIVITAS PENGGUNAAN EDMODO TERHADAP KEPUASAN SISWA DI SMKN 1 SURABAYA"

Berdasarkan hasil meta-analisis dari peneliti mengenai jurnal tersebut adalah indikator peserta didik belum merasakan manfaat edmodo dalam pembelajaran sehingga akan berpengaruh terhadap kepuasan siswa terhadap semua konten edmodo, sehingga tidak memanfaatkan untuk diskusi, hal ini juga dipengaruhi oleh keaktifan guru dalam mengakses edmodo. Namun, secara umum efektivitas penggunaan edmodo adalah tinggi serta tingkat kepuasan peserta didik adalah tinggi.

\section{KESIMPULAN DAN SARAN}

\section{Kesimpulan}

Jadi efektivitas belajar siswa secara daring menggunakan aplikasi edmodo yaitu, sebagai berikut:

1. pengaruh penggunakan aplikasi edmodo sangat mudah digunakan oleh pendidik dan peserta didik

2. aplikasi edmodo dapat mempengaruhi motivasi belajar peserta didik

3. edmodo dapat memudahkan peserta didik dalam mengerjakan soal dan mendiskusikan contoh soal dengan pendidik atau ke peserta didik lainnya

4. ada factor yang mempengaruhi efektivitas belajar menggunakan edmodo yaitu factor internal dan factor eksternal

5. kurang dimanfaatkan secara maksimal oleh pendidik maupun peserta didik

6. masih terdapat bahwa akses edmodo yang lambat membuat pendidk dan peserta didik kurang puas

\section{Saran}

Berdasarkan kesimpulan dan hasil penelitian yang telah dilakukan, ada saran dari peneliti yang ingin disampaikan yaitu:

1. Bagi peneliti yang ingin melakukan penelitian seperti ini harus mempunyai sumber yang banyak agar hasil penelitian yang lebih akurat.

2. Adanya pengembangan penelitian dalam menyusun rancangan penelitian agar media pembelajaran aplikasi edmodo dapat meningkatkan efektivitas belajar siswa.

\section{DAFTAR PUSTAKA}

Nasrullah Anton, Ende, dan Suryadi. 2017. Efektivitas penggunaan media edmodo pada pembelajaran matematika ekonomi 
terhadap komunikasi matematis.

Pasundan : Journal of Research in Mathematics Learning and Education, Vol II No.1, Juni 2017.

Ompusunggu, Vera Dewi Kartini dan Nilam Sari. 2019. "Efektivitas Penggunaan ELearning Berbasis Edmodo Terhadap Kemampuan Komunikasi Matematika". Curere : University Quality, Vol III No.2, Oktober 2019.

Tumangkeng, Yenti Winataria, Edy Yusmin dan Agung Hartoyo. 2018. "Meta Analisis Pengaruh Media Pembelajaran Terhadap Hasil Belajar Matematika Siswa". Pontianak : Jurnal Universitas Tanjungpura Pontianak.

Fitriasari, Putri. 2017. "Aplikasi Edmodo Sebagai Media Pembelajaran ELearning". Palembang : Jurnal Universitas PGRI Palembang.

Mahmud, Hilal dan Iqbal. 2019. "Pembelajaran Berbasis Edmodo Dan Motivasi Belajar Peserta Didik Di SMKN 2 Palopo". Towuti Luwu Timur : Journal Of Islamic Education Management.

Nu'man, Ahmad Zanin. 2014. "Efektivitas Penerapan E-Learning Model Edmodo Dalam Pembelajaran Pendidikan Agama Islam Terhadap Hasil Belajar Siswa". Sukoharjo : Duta.com.

Imam, F. (2013). "Efektifitas E-learning Melalui Edmodo terhadap Hasil Belajar Peserta Didik pada Materi Statistika SMA". Semarang : FKIP PGRI Semarang.

Aji, Kurniawan Fatwa. 2017. "Pengaruh pembelajaran Berbasis Website Terhadap Motivasi dan Hasil Belajar Siswa". Cirebon : Tadris IPA : IAIN Syekh Nurjati Cirebon, vol.6 nomor 1 , 2017.
Ali Sarino dan Tri Hikmawan, "Pemanfaatan Media Pembelajaran Berbasis EdmodoTerhadap Motivasi Siswa Sekolah Menengah Kejuruan”. Bandung : Jurnal Pendidikan Manajemen Perkantoran, Universitas Pendidikan Indonesia, Volume 1 nomor 2, 2018

Nur, Hidayat Wahyu dan Admaja Dwi Herlambang. "Edmodo untuk Meningkatkan Kualitas Perencanaan Proyek dan Efektivitas Pembelajaran di Lingkungan Pembelajaran yang Bersifat Asinkron". Malang : Jurnal. Pendidikan Teknologi Informasi, Fakultas Ilmu Komputer, Univeritas Brawijaya Politeknik Negeri Malang. 2016. 